\title{
Application of Carbon Nanobeads Prepared from Castor Seeds as a Sensor for the Detection of Estradiol
}

\section{Swapna Gijare*1, Suma Jebin², Umesh Mhapankar ${ }^{3}$}

${ }^{*}$ Assistant Professor, Department of Humanities and Basic Sciences, Fr. C. Rodrigues Institute of Technology, Vashi, Navi Mumbai, India

${ }^{2}$ Assistant Professor, Department of Humanities and Basic Sciences, Fr. C. Rodrigues Institute of Technology, Vashi, Navi Mumbai, India

${ }^{3}$ Assistant Professor, Department of Industrial Electronics, Fr. Agnel Polytechnic, Vashi, Navi Mumbai, India

\begin{abstract}
This paper presents the application of Carbon Nano beads (CNBs) prepared from castor seeds as a precursor by CVD method as a sensor to determine the concentration of estradiol in the urine sample. Semiconductors are the key for fabricating sensors. The semiconducting nature of prepared CNBs has been confirmed by photoluminescence (PL) technique. The required study for determining the hormone content of the urine sample in the presence of CNBs as a sensing material has been carried out using a CNB jig. The output voltage of the jig for the samples as well as standard solution of estradiol has been measured and calibrated into the concentration of estradiol in $\mu \mathrm{g} / \mathrm{ml}$. This sensor is a non-invasive, cheap, faster, simple to fabricate as compared to conventional diagnostic methods available.
\end{abstract}

Keywords : Carbon Nano Beads,Estradiol, Non-Invasive, Concentration

\section{INTRODUCTION}

Hormones are the substances produced by the endocrine glands that have chemical effect on the other parts of the body. Women produce hormones like estradiol (estrogen), Follicle Stimulating Hormone (FSH), Luteinizing Hormone (LH) and progesterone. Certain hormones rise at the various times of menstrual cycle and during pregnancy. Estrogen is the predominant female hormone. Estradiol is the major form of estrogen produced in the ovary. On the first day of Menstrual cycle, estrogen and progesterone levels are low which signal the pituitary gland to produce FSH.FSH begins the process of maturing a follicle.
Follicle produces more estrogen to prepare uterus for pregnancy. At ovulation, usually around 12th to 14th day, increased estrogen level triggers a sharp rise in LH from pituitary gland causing release of egg from the follicle. Ruptured egg secretes progesterone and estrogen to continue to prepare uterus for pregnancy. If egg is not fertilized, estrogen and progesterone levels drop on 28th day and menses begin. The Female hormone cycle showing the estrogen and progesterone level is shown in Figure.1.

Estrogen is the main regulator of female reproductive system. Generally, its concentration can be detected through blood samples by a routine invasive method. There is a need for development of hormone sensor which could simplify the understanding and hence will enable the treatment of infertility, menopause 
and other conditions of hormonal imbalances. Women also can use them easily as they detect estrogen from urine samples and moreover, they are reusable.

Carbon nanomaterials (CNMs) are surface structures and therefore, have a predetermined electrochemical and adsorption properties. This makes them a promising starting material for the development of super miniaturized chemical and biological sensor of a high sensitivity. The operation principle of these sensors is based on changes in the V-I curves of nanobeads as a result of adsorption of specific molecules on their surface. With CNMs, the detection of several analytes is possible at low applied potential without using any electronic mediators and hence interferences can be reduced.

\section{METHODS AND MATERIAL}

\section{A. Preparation of CNBs}

Castor seeds were selected as the precursor. An initial elemental analysis of seeds was done to get an idea about the Carbon content. Castor seeds were found to contain $55.728 \%$ carbon. Castor seeds contain $12-15 \%$ water, to remove the water from seeds they were kept in a hot air oven at $100^{\circ}$ $\mathrm{C}$ for one hour, and then crushed to form powder. Iron $(\mathrm{Fe})$ was used as catalyst for Carbon Nano beads (CNBs) synthesis because of their high solubility in carbon at high temperature and high carbon diffusion rate. A Horizontal CVD furnace was used for synthesis of CNBs from castor seeds. Pyrolysed product, along with carbon also contains remnants of metal catalyst, some amorphous carbon, possibly same as and other impurities. To get pure $\mathrm{CNB}$, the product obtained from pyrolysis was suspended in $1 \mathrm{~N} \mathrm{HCl}$ and kept on stirrer overnight. Then it was filtered through Buckner funnel with the help of Whatman filter paper and finally dried in a muffle furnace at $60^{\circ} \mathrm{C}$ for $30 \mathrm{~min}$. Purified CNBs were weighed. The morphological observations of as-synthesized and purified CNB were carried out by Scanning Electronic Microscope (SEM).

\section{B. Preparation of standard solution of estradiol} $10 \mathrm{mg}$ estradiol (purity 99\%) is weighed accurately and transferred to $250 \mathrm{ml}$ beaker. $100 \mathrm{ml}$ Dimethyl sulphoxide (DMSO) with 99\% purity is accurately measured using $100 \mathrm{ml}$ standard volumetric flask and is added to the beaker containing estradiol with intermittent stirring with the help of glass rod. This gives the standard solution of estradiol of strength $0.1 \mathrm{mg} / \mathrm{ml}$. Similarly the standard solution of progesterone of strength $2.5 \mathrm{mg} / \mathrm{ml}$ has also been prepared.

C. Response of Carbon Nanobeads (CNBs) sensor with standard hormone solutions of estradiol and Progesterone

Testing is carried out by designing a simple circuit containing capacitor, resistor and $9 \mathrm{~V}$ battery which shown in Figure.2. The voltage across the capacitor using standard solutions of estradiol with CNBs (thin and thick layer separately) has been measured and tabulated in Table.1. This has been done by increasing the amount of estrogen by simply increasing the number of drops of solution. The output voltage decreases with the increasing concentration of estradiol.

D.Testing of estrogen levels in different age group subjects and their comparison with standard response In order to test the sensing ability of CNBs towards female hormones, urine sample of healthy woman as well as the one with hormonal imbalances (age group 25 to 50 years) at different stages of menstrual cycle is 
used. The observations for the same are tabulated in Table.2

The Calibration of voltage into estrogen level is done as follows: -

From the preparation of the standard solution of estadiol, its strength is calculated as $0.1 \mathrm{mg} / \mathrm{ml}$.

Amount of estrogen per $\mathrm{ml}$ is $0.1 \mathrm{mg}$. Amount of estrogen per drop (Appx.0.1 ml) is $0.01 \mathrm{mg}$. Amount of estrogen in 5 drops is $0.05 \mathrm{mg}$ i.e. $50 \mu \mathrm{g}$.The voltage drop corresponding to 5 drops of estrogen 0.65 Volts. Conversely, $0.65 \mathrm{~V}$ corresponds to $50 \mu \mathrm{g} .0 .65 \mathrm{~V}$ is approximately $1 \mathrm{~V}$ i.e. $1 \mathrm{~V}$ corresponds to $50 \mu \mathrm{g}$.

This shows that as the concentration of estrogen increases, the voltage decreases. Therefore, in order to calibrate the voltage into estrogen concentration, it is decided to take the output across the resistive network instead of sensor (capacitor). The output from sensor is connected to voltmeter through buffer circuit with a calibrating potentiometer. The voltmeter display will correspond to voltage with last three digits and a decimal point before the last digit. Voltmeter is calibrated in linear term so that the display value corresponds to the concentration of the estrogen in the sample. The required circuit diagram is shown in figure. 3

\section{RESULTS AND DISCUSSION}

As the estrogen content increases, the voltage decreases. As the thickness of CNB increases the voltage decreases as thicker CNBs adsorb more estrogen. It was found that CNB does not adsorb any progesterone as no change in the voltage was observed either with thicker or thinner layer of CNBs. This may be due to the presence of carbonyl group in progesterone structure. Estradiol contains hydroxyl group and not carbonyl. This could be the reason for difference in their conductivity. (Estradiol is an alcohol whereas progesterone is a ketone).

a) Subject A and Subject B :-

1) Initial 5 days of menstrual cycle, the estrogen level is low. This is indicated by the high voltage.

2) Approximately in the middle of the cycle (1415th day) when ovulation occurs, the estrogen level is at the peak which is indicated by the low voltage.

3) At the post ovulation stage, again estrogen level decreases which is indicated by high voltage.

b) Subject C and D:-

The voltage being same at all the 3 stages indicates the hormonal imbalance, which may be indicative of Polycystic Ovarian Disease (PCOD). This can be further correlated with conventional blood tests and other diagnostic methods.

c) Subject E:-

Continuous decrease in the voltage shows that the estrogen levels are almost constant throughout the month which is again indicative of menopausal stage.

\section{IV.CONCLUSION}

Response of Carbon Nanobeads (CNBs) sensor with standard hormone solutions of estradiol and Progesterone and with the urine samples of various subjects is studied and compared. It was observed that with increase in the concentration of estrogen and the thickness of layer of CNBs, the voltage decreases. Hence it can be concluded that CNBs can be used to detect the levels of estrogen. This can be used as effective and quick Non-invasive diagnostic technique for checking hormone profile. Progesterone levels cannot be detected. 


\section{REFERENCES}

[1]. Maheshwar Sharon and Madhuri Sharon, "Carbon Nanomaterials: Applications in Physico-chemical Systems and Biosystems"Defence Science Journal, Vol. 58, No. 4, July 2008, pp. 460-485.

[2]. Abdulazeez T lawal, "Synthesis and utilization of carbon nanotubes for fabrication of electrochemical biosensors", Material Research Bulletin, Volume 73, January 2016, pp 308-350

[3]. Robert J. Chen, HeeCheul Choi, SarunyaBangsaruntip, ErhanYenilmez,Xiaowu Tang, Qian Wang, Ying-Lan Chang, andHongjie Dai," An Investigation of the Mechanisms of Electronic Sensing of Protein Adsorption on Carbon Nanotube Devices"J. Am. Chem. Soc., 2004, 126 (5), pp 1563-1568

[4]. LihuaYuan,JunZhang,PingZhou,JiaxingChen, R uoyuWang,TingtingWen, YunLi,XueminZhou, HuijunJiang,"Electrochemical sensor based on molecularly imprinted membranes at platinum nanoparticles-modified electrode for determination of $17 \beta$-estradiol"Biosensors and bioelectronics, volume29, Issue1, 15 November 2011, pp29-33.

[5]. SwapnaGijare, Suma Jebin, UmeshMhapankar"A scope of using carbon nanobeads prepared from castor seeds as biosensors"International Journal of Scientific Research in Science and Technology" 2017, Volume 3, Issue 10, pp 33-38

[6]. Sandeep Kumar Vashist,Dan Zheng, Khalid AlRubeaan,John H.T. Luong,Fwu-Shan Sheu,"Advances in carbon nanotube based electrochemical

sensors for bioanalyticalapplications",Biotechnology advances 29 (2011),pp169,188.

[7]. SwapnaGijare, SumaJebin ,Madhuri Sharon, "Impact of Catalyst on the Synthesis of Carbon Nano Materials from Castor Seeds by CVD method"Advanced science letters vol.22. No.4,(April 2016),pp.715-1092).

[8]. Mohammed Al Araimiet.al,'Adioxoborine cyanine dye as a photoluminescence for sensing carbon nanotubes', Beilstein Journal of Nanotechnology, pp1991-1999.

[9]. M.A.Lopez-Gordo, D. Sanchez-Morillo, F.Pelayo Valle, Dry EEG Electrodes, sensors2014,ISSN 1424-8220, pp:12847- 12870.

[10]. Kumar M et al.in "Nano forms of Carbon and its application" Ed. by Maheshwar Sharon\&Madhuri Sharon. Monad Nanotech Publisher, Mumbai, India, 2007.

[11]. Sharon Maheshwar\&Madhuri Sharon. Carbon Nanoforms -Application.McGraw Hill, USA, 2010 .

\section{Cite this article as :}

Swapna Gijare, Suma Jebin, Umesh Mhapankar, "Application of Carbon Nanobeads Prepared from Castor Seeds as a Sensor for the Detection of Estradiol", International Journal of Scientific Research in Science and Technology (IJSRST), Online ISSN : 2395-602X, Print ISSN : 2395-6011, Volume 6 Issue 4, pp. , July-August 2019. Available at doi : https://doi.org/10.32628/IJSRST196348 Journal URL : http://ijsrst.com/IJSRST196348 
TABLE: 1 THE VOLTAGE ACROSS THE CAPACITOR WITH CNBS FOR STANDARD SOLUTIONS

\begin{tabular}{|c|c|c|c|c|}
\hline $\begin{array}{l}\text { Sr. } \\
\text { No }\end{array}$ & Condition & No.of drops & $\begin{array}{c}\text { Voltage } \\
\text { (With thin layer of } \\
\text { CNB) }\end{array}$ & $\begin{array}{c}\text { Voltage } \\
\text { (With thick layer of CNB) }\end{array}$ \\
\hline 1. & $\begin{array}{c}\text { Without any } \\
\text { hormone solutions. }\end{array}$ & - & $9.21 \mathrm{~V}$ & $6.47 \mathrm{~V}$ \\
\hline \multirow{4}{*}{2.} & With estrogen & 1 drop & 8.5 & 6.47 \\
\hline & & 2 drops & 8.22 & 6.20 \\
\hline & & 3 drops & 8.10 & 4.20 \\
\hline & & 5 drops & 7.91 & 0.65 \\
\hline \multirow[t]{3}{*}{3} & With Progesterone & 1 drop & 9.10 & 9.10 \\
\hline & & 2 drops & 8.39 & 9.10 \\
\hline & & 3 drops & 8.39 & 9.10 \\
\hline
\end{tabular}

TABLE: 2 THE OUTPUT VOLTAGE ACROSS THE CAPACITOR WITH CNBS FOR VARIOUS CONDITIONS OF THE SUBJECTS.

\begin{tabular}{|c|c|c|c|}
\hline Subject & $\begin{array}{c}\text { Voltage } \\
\text { (Day 1-5 of Menstrual } \\
\text { Cycle) }\end{array}$ & $\begin{array}{c}\text { (15 } 5^{\text {th }} \text { Day of Menstrual } \\
\text { cycle })\end{array}$ & $\begin{array}{c}\text { (Day } 20 \text { of menstrual } \\
\text { cycle) }\end{array}$ \\
\hline A (age 25 years) & 8.3 & 2.3 & 5 \\
\hline B (age 25 years) & 8.4 & 3.7 & 4 \\
\hline $\begin{array}{l}\text { C (PCOD patient age } \\
28 \text { years) }\end{array}$ & 7.2 & 7.6 & 7.3 \\
\hline $\begin{array}{l}\mathrm{D} \text { (PCOD patient age } \\
32 \text { years) }\end{array}$ & 6.8 & 6.5 & 6.2 \\
\hline $\begin{array}{c}\text { E (Menopause stage } \\
\text { age } 50 \text { years) }\end{array}$ & 8.3 & 6.7 & 5 \\
\hline
\end{tabular}




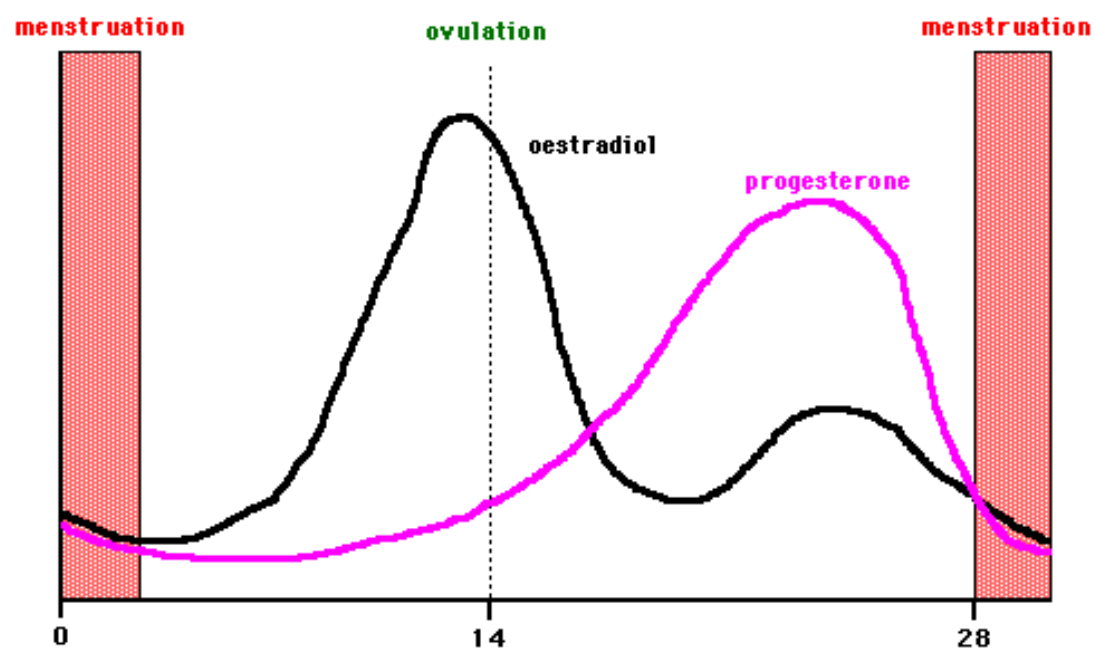

FIGURE.1.THE FEMALE HORMONE CYCLE SHOWING THE ESTROGEN AND PROGESTERONE LEVELS.

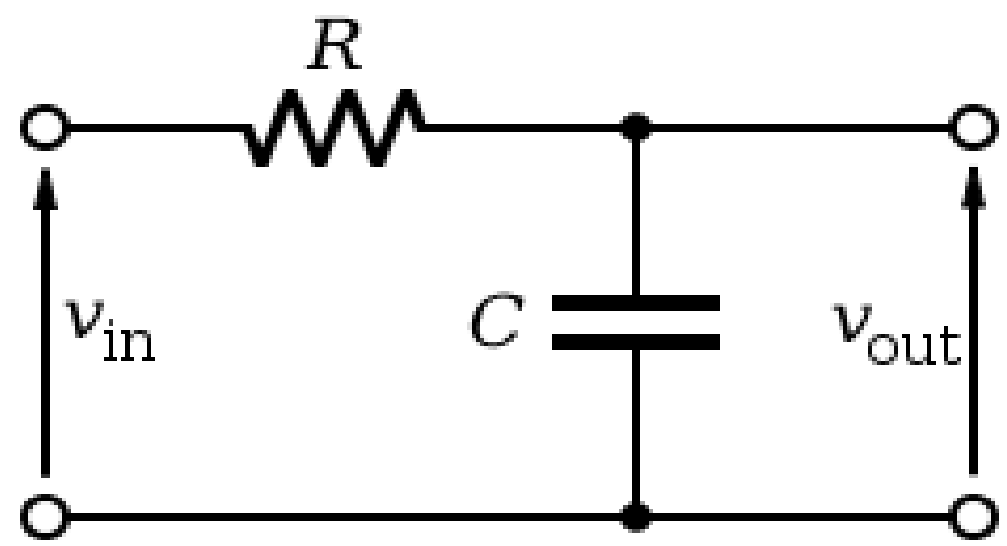

FIGURE 2. CIRCUIT DIAGRAM TO TEST THE SENSING ABILITY OF CNBS TOWARDS FEMALE HORMONES

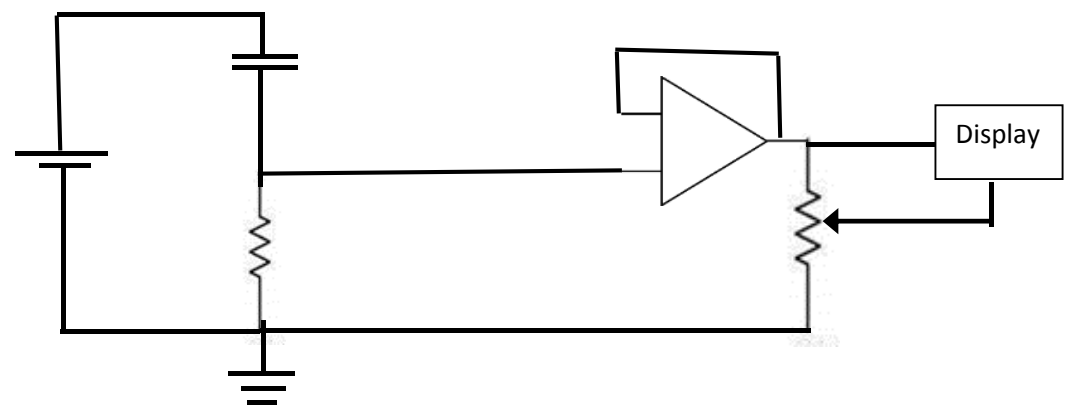

FIGURE 3. CIRCUIT DIAGRAM TO TEST THE SENSING ABILITY OF CNBS TOWARDS FEMALE HORMONES 